\title{
Histological Changes in the Cervical Cells Associated with Hormonal Contraception
}

\author{
Wala M Elfatih Mahgoub ${ }^{1 *}$ and Ibrahim A Ali ${ }^{2 *}$ \\ ${ }^{1}$ Department of Anatomy, The National Ribat University, Sudan \\ ${ }^{2}$ Department of Physiology, The National Ribat University, Sudan
}

Submission: September 14, 2018 ; Published: October 05, 2018

*Corresponding author: Wala Mohamed Elfatih Mahgoub AbdAlla, Department of Anatomy, Faculty of Medicine, The National Ribat University, Khartoum, Sudan; Email: walla_9@live.com

*Ibrahim A Ali , Department of Physiology, Faculty of Medicine, The National Ribat University, Khartoum, Sudan; Email: hemamedicine@gmail.com

\section{Introduction}

Around the world, contraception has been used, in one form or another, for thousands of years. Many women use it for extremely long periods of time during their reproductive lifespan. There are different types of contraception that could be used by women at different stages in their lives and no one method that suits everyone. There are different types of contraceptives such as; combined hormonal contraception, progesterone only preparations, intrauterine contraception and barrier methods [1].

The combined oral contraception (COC)-"the pill"- contains a mixture of two hormones a synthetic estrogen and a synthetic form of progesterone. It is estimated that at least 200 million women worldwide have taken COC since it was first marketed. The COC affects almost all the systems in the body such as the nervous system in form of mood changes and headache, the gastrointestinal tract in form of nausea and liver cirrhosis, the breasts in form of breast pain, vascular system in form of venous thromboembolism and hypertension, reproductive system in form of vaginal discharge and cervical abnormalities [1,2].

Progestin-Only Pills, often called "minipills," inhibit ovulation in about 50 percent of women. Their primary mechanism of action is thickening of the cervical mucus. This effect occurs within hours of taking a progestin-only pill and peaks about four hours after the pill is taken [3].

The injectable contraceptives contain a progestin like the natural hormone progesterone in a woman and do not contain estrogen, and so can be used throughout breastfeeding and by women who cannot use methods with estrogen [4].

The subdermal implant (Implanon) is inserted subdermally under local anaesthetic into the upper arm. It releases the progestogen etonogestrel and lasts for three years and thereafter can be easily removed and another one could be inserted if requested [1]. The cervix is the lower cylindrical part of the uterus; its internal aspect which is closed to uterus lined with simple columnar epithelium and the external aspect that bulges into the lumen of the vagina is covered with stratified squamous epithelium [5].

During the proliferative (estrogenic) phase of menstrual cycle where the endogenous estrogen reaching its peak proliferation and reconstituting the endometrium that lost during menstruation takes place. In this phase the epithelium lining of the endometrium changes from a single layer of columnar cells to psudostratified epithelium with frequent mitosis and the endometrial thickness increases rapidly from $0.5 \mathrm{~mm}$ at menstruation to $2-3 \mathrm{~mm}$; while in secretory phase, progesterone induces the formation of a temporary layer, known as the decidua, in the endometrial stroma. Histologically, this is seen as occurring around blood vessels. Stromal cells show increased mitotic activity, nuclear enlargement and generation of a basement membrane. In this phase, the endometrium reaches its maximum thickness $(5 \mathrm{~mm})$ as a result of the accumulation of secretions and edema in the stroma $[1,5]$.

It is known that both estrogen and progesterone affect the differentiation and proliferation of the epithelial lining of the endometrial layer of the uterus during their menstrual cycle. Hormonal contraception depends upon administration of exogenous forms of either progesterone or both estrogen and progesterone, these exogenous hormones affecting the endometrial layer of the uterus in response to their steady concentrations of the blood especially for a long time [3].

\section{Methods of Contraception}

Contraception, also known as birth control and fertility control, is a method or device use to prevent pregnancy. Contraception has been used, in one form or another, for many decades. Many women will use it for extremely long periods of time in their reproductive lifespan. Women use different types of contraception at different stages in their lives and there is no one method that will suit everyone. There is no perfect method of contraception and each method will have a balance of advantages and disadvantages. An ideal contraceptive method should be; highly effective, no side effects or risks and cheap [1]. 


\section{Journal of Gynecology and Women's Health}

There are many and different methods of contraception including; combined hormonal contraception, among these there are: the pill, patches and vaginal ring; the commonest method used for lactating mothers is progesterone -only preparations, which include, POP, injectables, and subdermal implants; also there are hormonal emergency contraception and intrauterine contraception which occurs in form of copper intrauterine device (IUD) and hormone-releasing intrauterine system (IUS); barrier methods are globally used and includes, condoms, female barriers (fandom), coitus interrupts and natural family planning; less used methods may be of the surgical hazard associated are, female sterilization and vasectomy $[1,4]$.

Combined hormonal contraceptives (COCs) are one of the most popular methods of birth control, worldwide. This reliable form of contraception may have several contraindications to use. In fact COCs could induce adverse effects, most of them not serious but some which can be life threatening.

Abnormal uterine bleeding is a common side effect of all forms of hormonal contraception. Combined oral contraceptives are classified by the International Agency for Research on Cancer as a cause of cervical cancer $[3,7]$.

Progesterone-only contraception avoids the risks and side effects of estrogen. All Progesterone-only methods work by a local effect on cervical mucus by inducing proliferative effects in the epithelial cells and on the endometrium, by making it thin and atrophic, thereby preventing implantation and sperm transport $[1,5]$.

Progesterone only pill (POP) is taken every day without a break. It is ideal for women at times of lower fertility. If the POP fails, there is a slightly higher risk of ectopic pregnancy. POPS have many side effects including Changes in bleeding patterns in forms of frequent bleeding, Irregular bleeding, Infrequent bleeding and Prolonged bleeding beside it is reported to cause headaches, dizziness, mood changes, breast tenderness and abdominal pain. At biochemical level progesterone is known to oxidize LDL with subsequent arterial injury [1,7]. Two injectable forms of progesterone are widely distributed depo-provera $(150 \mathrm{mg})$ and norethisterone enanthate (200mg) [1] (Figures 1\&2).

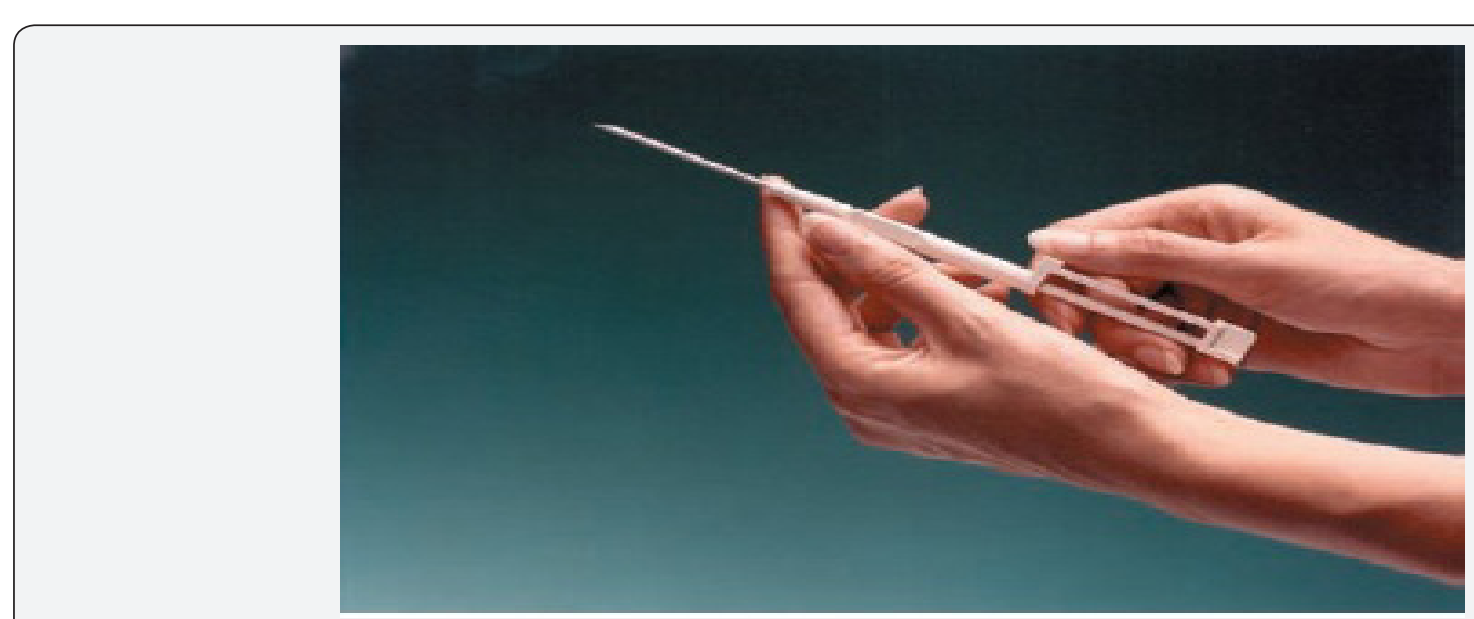

Figure 1: Shows subdermal Implants Injection.

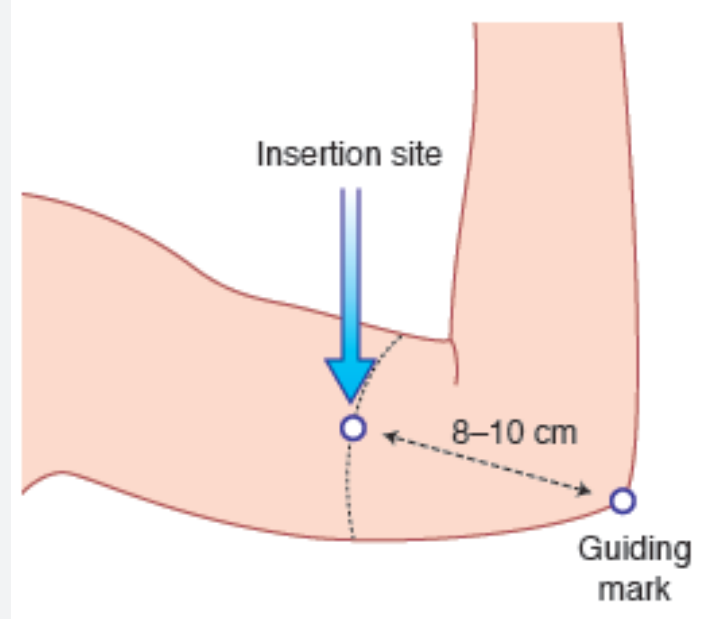

Figure 2: Insersion postion of Implanon. 
Most women choose depo-provera and each injection lasts for 12 weeks with a 2-week grace period, norethisterone enanthate only lasts for 8 weeks and is not nearly so widely used. DepoProvera is highly effective and causes low estrogen levels and this is associated with loss of bone mineral density. Bone density seems to recover when Depo-Provera is stopped. Women with preexisting risk factors for osteoporosis should probably be advised not to use Depo-Provera in the long term. Particular side effects of Depo-Provera include: weight gain, delay in return of fertility, persistently irregular periods $[1,3,5]$.

Implanon consists of a single (silastic rod) that is inserted subdermally under local anaesthetic into the upper arm. It releases the progestogen etonogestrel $25-70 \mathrm{mg}$ daily (the dose released decreases with time), which is metabolized to the thirdgeneration progestogen desgestrel. It lasts for three years and thereafter can be easily removed and a further implant inserted if requested [1].

The aim of this review is to detect early changes in cervical cytological smears and to correlate these finding to the possibility of developing serious conditions that could be prevented. Persistent consumption of hormonal contraception especially for long duration of time might lead to serious cervical abnormalities in form of dysplastic changes or even cervical carcinoma. Many factors might contribute to presence or absence of cervical abnormalities such as duration of consumption of hormonal contraception, age, work and the type of hormonal contraception used. Worldwide it is estimated that more than 200 millions of women using different forms of hormonal contraception [1]. Thus, the ultimate goal of this review is to detect early minor changes that occur in cervical mucosa in relation to the use of hormonal contraception, it is an attempt to avoid the serious complications that may follow; i.e. cervical intraepithelial neoplasia (CIN) or even an invasive carcinoma which might be at the expense of time and money and may lead to unfortunate death which could be avoided.

\section{Cervical Intra-Epithelial Neoplasia (CIN)}

Cervical intra epithelial neoplasia (CIN) also known as dysplasia, is defined as a spectrum of intraepithelial changes that begin as well differentiated intra epithelial neoplasm and classified as a mild dysplasia, and ends with invasive cancer [8]. The neoplastic changes are confined to the squamous epithelium and include nuclear pleomomphism (abnormal chromatin aggregates), loss of polarity with increase in the nuclear/cytoplasmic ratio and the presence of abnormal mitoses (mitotic figures) [8].

CINCIN is graded from 1-3; the grading is based on the amount of undifferentiated cells present from the basement membrane to the surface epithelium. When up to one-third of this distance is involved the grade is CIN1, when more than one-third and up to two-thirds is involved the grade is CIN2, and when more than two-thirds are involved the grade is CIN3. When the patient has full thickness involvement from the basement membrane to the surface epithelium, this condition is referred to as carcinoma in situ (CIS). Although the current thory is that CIS is part of the spectrum of CIN. While the presence of CIN 3 implies a greater risk for the development of invasive cancer than does the presence of CIN 1 or 2, it is only a relative risk. There are currently no objective markers of increased risk for invasion. These are desperately needed in order to plan interventions and assess their impact $[8,9]$ (Figure 3).

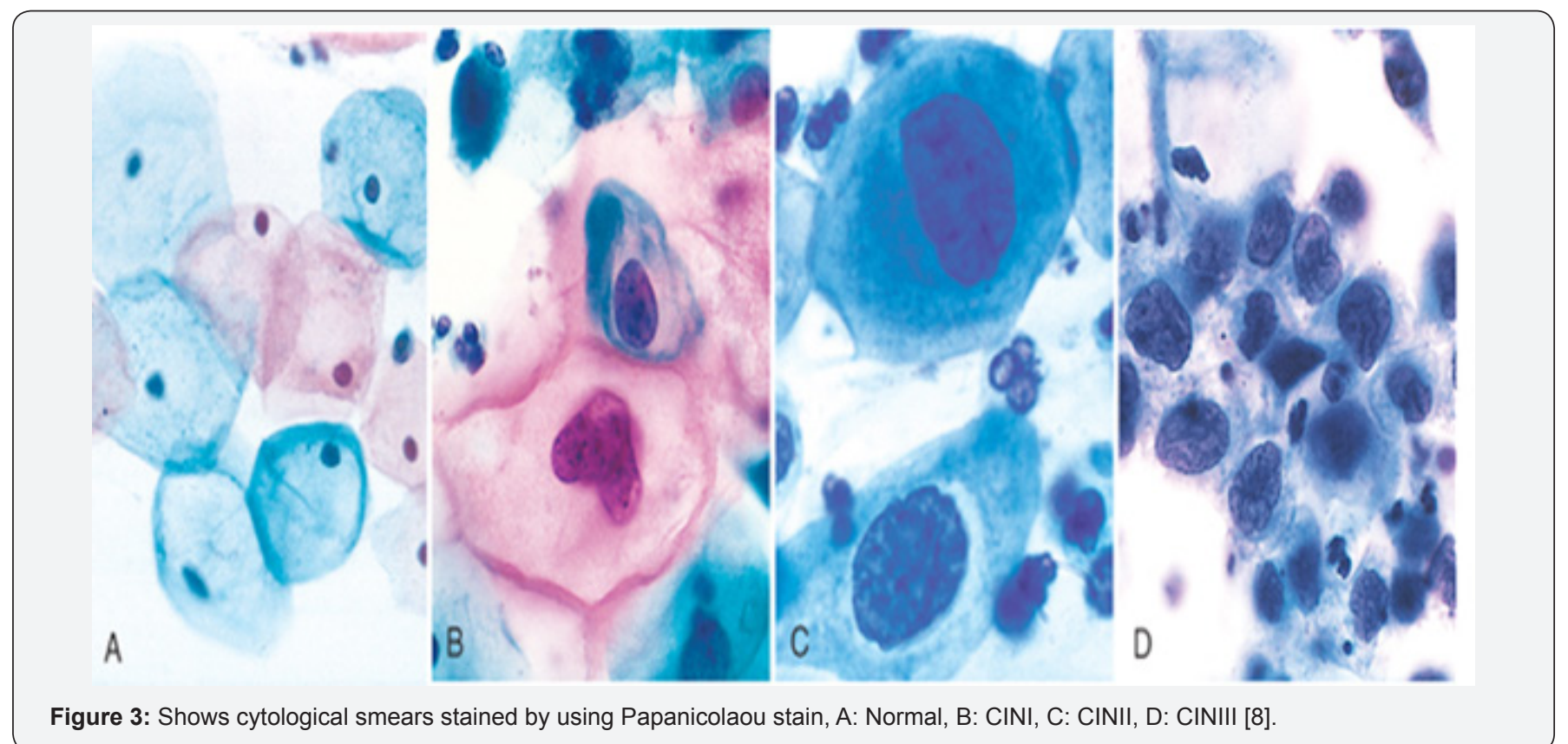

\section{Cervical Carcinoma}

It is an invasive carcinoma that arises from the cervical epithelium. Most commonly seen in middle aged women (average age is $40-50$ years). This condition presents mainly as vaginal bleeding, especially post-coital, or cervical discharge. Risk factors include; HPV infection, immunodeficiency status, smoking and OCP which considered as a cause of early cytological abnormalities of cervical exfoliated cells. The most common subtypes of cervical 


\section{Journal of Gynecology and Women's Health}

cancer are squamous cell carcinoma (80\%) and adenocarcinoma (15\%). Advanced tumors often invade through the anterior uterine wall into the urinary bladder, blocking the ureters. Hydronephrosis with postrenal failure is a common cause of death in advanced cervical carcinoma $[2,10]$.

\section{Results of Previous Studies}

A study done by Brinton L, Reeves WC et al, in Entebbe, Uganda, in September 2013 ; concluded that the recent long terms users of (COC) at high risk of developing invasive cervical carcinoma with RR=1.7 [6]. An article done by R. Sabatini1, R. Cagiano et al, stated that current users of combined oral contraceptives have an increased risk for cancer of the cervix, breast, and liver compared with non-users, while it was generally reported that current users of combined oral contraceptives have a reduced risk of cancer of the endometrium, ovaries, and possibly, colorectum. Also, they stated that cervical cytological studies reported the significantly high frequency of squamous intraepithelial lesions (SILs) in the early stages of contraception with Norplant insertion, but after 1 year a progressive decline of them was found and after 3 years no SIL was seen [7].

Combined oral contraceptives are classified by the International Agency for Research on Cancer as a cause of cervical cancer [7]. A study done by Appleby P, Beral V, et al as part of the international collaboration of epidemiological studies of cervical cancer in 2007, stated that among current users of oral contraceptives the risk of invasive cervical cancer increased with increasing duration of use (relative risk=RR for 5 or more years' use versus never use, 1.90) [8].

A prospective cohort study- done by Beral V, Hannaford, et al, in the Royal college of general practioners'-of 47000 women followed since 1968, which stated that, those who used OCP had a significant higher incidence rate of cervical cancer than neverusers and the standardized incidence rate for cervical cancer in women who had taken the pill for more than 10 years was 4 times that in never-users [11].

A study done by Diaz J, et al. [12] in Brazil concluded that bleeding side effects is a major reason for discontinuation. In this study, discontinuation was more closely related to increased or decreased bleeding than to irregular, unpredictable bleeding. At biochemical level progesterone is known to oxidize LDL with subsequent arterial injury [7].

Mahgoub etal. [13] found thatUsage of hormonal contraception is linked to increase the possibility of developing dysplastic changes in the cervical exfoliated cells which in turn harboring the potentiality of developing cervical cancer. There is strong association between the duration of hormonal contraception usage and dysplastic changes in the cervical exfoliated cells.

\section{Conclusion}

a) Usage of hormonal contraception is linked to increase the possibility of developing dysplasia which in turn harboring the potentiality of developing cervical cancer. b) There is strong correlation between the duration of hormonal contraception usage and dysplastic changes on the cervical exfoliated cells.

c) The Incidence density of dysplastic changes on the cervical exfoliated cells among the exposed group was higher than that of the not-exposed group.

d) Interpretation of the Risk Ratio concluded that, the women who used hormonal contraception were 4 times more likely to develop dysplastic cervical lesions in comparison with those who did not use hormonal contraception.

\section{Recommendations}

a) Health education sessions should be conducted to the medical personnel who dealing with hormonal contraception regarding the potential side- effects of them.

b) Hormonal contraception should be prescribed by a trained doctor or midwife after taking a detailed history from the user, and a clear instruction about when to stop the hormonal contraception should also be provided.

\section{References}

1. Bewley S, Cheong Y (2011) Fertility control, contraception and abortion. In: Ash Monga, Stephen Dobbs. (eds.), In: (19 $9^{\text {th }}$ edn), Gynaecology. Hodder Arnold, London, UK, pp. 62-70.

2. Negrini BP, Schiffman MH (1990) Oral contraceptive use, human papilloma virus infection and risk of early cytological abnormalities of the cervix. Cancer Res 50(15): 4670-4675.

3. Schrager S (2002) Abnormal uterine bleeding associated with hormonal contraception. Am Fam Physician 65(10): 2073-2081.

4. World Health Organization (2011) Family Planning: a global Handbook for providers. Update: evidence- based guidance developed through worldwide collaboration. World Health Organization, Geneva, pp. $1-183$.

5. Junqueira LC, Caeneiro J (2005) Female genital histology. In: Junqueira (eds.), In: $\left(12^{\text {th }}\right.$ edn), Basic histology. McGraw-Hill Medical, New York, USA, 20.

6. Brinton LA, Reeves WC, Brenes MM, Herrero R, Britton DRC, et al. (1990) Oral contraceptive use and risk of invasive cervical cancer. Int J Epidemiol 19 (1): 4-11.

7. Sabatini R, Cagiano, Rabe T (2001) Adverse Effects of Hormonal Contraception. Journal Fur Reprodukionsmedizin und Endokrinologie Journal of Reproductive Medicine and Endocrinology 8(1): 130-156.

8. Ferenczy A, Winkler B (1986) Cervical intraepithelial neoplasia and condyboma: An analysis of diagnostic accuracy of posttreatment follow-up methods. American journal of obstetrics and gynecology 154(2): 260-264.

9. Boone C, Kelboff, G, Steele V (1992) The natural history of intraepithelial neoplasia in humans with implications for cancer chemoprevention strategy. Cancer Res 52(7): 1651-1659.

10. Sattar HA (2015) Female Genital System and Gestational Pathology. In: Husain A Sattar (eds.), In: ( $3^{\text {rd }}$ edn), Fundementals of Pathology. Pathoma LLC, USA, pp. 1-17.

11. Beral V, Hannaford P, Kay C (1998) Oral contraceptive use and malignancies of the genital tract. Royal College of general practitioners. Lancet 2(8624): 1331-1335.

12. Diaz J, Faundes A, Olmos P, Diaz M (1996) Bleeding complaints during the first year of Norplant implants use and their impact on removal rate. Contraception 53(2): 91-95. 
13. Mahgoub WME, Ibrahim AA, Mohamed K, Elbadawi K (2018) Histological Changes on Cervical Exfoliated Cells Following

(C) This work is licensed under Creative (1) Commons Attribution 4.0 License DOI: 10.19080/JGWH.2018.12.555833
Administration of a Hormonal Contraception. Glob J Reprod Med 4(5): 555646.

\section{Your next submission with Juniper Publishers will reach you the below assets}

- Quality Editorial service

- Swift Peer Review

- Reprints availability

- E-prints Service

- Manuscript Podcast for convenient understanding

- Global attainment for your research

- Manuscript accessibility in different formats

( Pdf, E-pub, Full Text, Audio)

- Unceasing customer service

Track the below URL for one-step submission https://juniperpublishers.com/online-submission.php 